\title{
Políticas de inclusão e relações com a diferença: considerações sobre potencialidades, transformações e limites nas práticas de acesso e permanência da UFG
}

Social inclusion policies and relations with difference: considerations about potentialities, transformations and limits in the UFG access and permanence practices

\footnotetext{
Alexandre Ferraz Herbetta*

* Universidade Federal de Goiás - Goiânia, GO, Brasil alexandre_herbetta@yahoo.com.br
} 


\title{
Resumo
}

O texto descreve e analisa algumas políticas de inclusão e permanência, efetivadas na UFG - Universidade Federal de Goiás, para coletivos culturalmente diferenciados. A partir da comparação entre duas delas, o programa UFGInclui e a criação do Núcleo Takinahakỹ de Formação Superior Indígena (NTFSI), busca-se refletir sobre ambiguidades, potencialidades e transformações observadas na universidade. Aventa-se a hipótese de que a agência de pessoas e coletivos é fundamental no processo de democratização universitária. E, fundamentalmente, que a universidade necessita de transformações estruturais para a concreta efetivação da inclusão e permanência.

Palavras-chave: inclusão; democratização; política; transformação.

\begin{abstract}
This article tries to describe and analyze some inclusion policies established at UFG - Federal University of Goiás. Based on the comparison between two of them, the UFGInclui program and the creation of the NTFSI - Takinahaky Indigenous Formation Center, aim to reflect on the university ambiguities, potentialities and transformations. It is hypothesized that the agency of people and collectives is fundamental in the process. And, fundamentally, that the university needs structural transformations for the concrete realization of the inclusion and permanence policies.
\end{abstract}

Keywords: inclusion; democratization; politics; transformation. 
Kbure akwẽ mnõ tâkãhã tkai wasissum snã krda mmrõ mnõwa psêdi kbure mã ("É importante conviver com a diversidade cultural, no mesmo espaço, na terra”).

Damsõkekwa Xerente (2016)

Em 2013 Ercivaldo Damsõkekwa Xerente, egresso do curso de Licenciatura Intercultural Indígena, do Núcleo Takinahakỹ de Formação Superior Indígena (NTFSI), da Universidade Federal de Goiás (UFG), resolveu seguir seus estudos em nível de pós-graduação. Ele havia finalizado a graduação, quando se focou na área da cultura, uma das matrizes curriculares do curso em referência. As outras matrizes são da área da linguagem e da natureza. Desejava cursar o Programa de Pós-Graduação em Antropologia Social (PPGAS), no nível de mestrado, na turma de 2014.

Damsõkekwa, cujo nome significa "o que abre trilhas", se preparou para o processo de seleção como todos os outros candidatos não indígenas, se deslocando para Goiânia no período do processo. Antes disso, redigiu um projeto intitulado Organização social e processos próprios de aprendizagem do povo akwẽ. Nele, buscava investigar a presença de práticas pedagógicas tradicionais na Escola Indígena Wakõmẽkwa, onde leciona, em sua aldeia xerente. E, além disso, buscava estabelecer uma relação interessante entre a organização social de seu povo e a noção de modos próprios de aprendizagem, presente no artigo 210 da Constituição Federal de 1988, o qual garante às escolas indígenas certa autonomia.

Apesar de ter o projeto, que foi avaliado por três professores da linha "Etnopolítica e processos de exclusão social”, no PPGAS, aprovado com destaque, demonstrando ótima capacidade de problematização da realidade, boa perspectiva antropológica e, além disso, propondo uma pesquisa bastante pertinente e atual ao campo de estudos da educação escolar indígena, não passou na prova escrita teórica. Esta cobrava um domínio de literatura antropológica, a partir da leitura de alguns textos indicados previamente e, também, a escrita dissertativa, típica da academia.

Conforme Ramos (2013), que passou a dirigir atenção metodológica e teórica aos modos próprios de comunicação de populações indígenas, devemos nos atentar a eles quando nos referimos à presença indígena na universidade. Para a autora, por exemplo, enquanto a academia tem aversão à repetição, os modos indígenas valorizam 
o uso da repetição e a extrema paciência para ouvir. Fosse na intimidade das aldeias, na impessoalidade de fóruns políticos ou na formalidade de encontros acadêmicos, percebi nesses traços a feição que distingue o modo indígena de se comunicar e que passei a admirar, embora sem a competência e a perseverança necessárias para emular de forma sustentada. Foi preciso me debruçar sobre questões de epistemologias transculturais e sobre políticas da diferença para que essas impressões se transformassem em objeto de reflexão antropológica. (Ramos, 2013, p. 6).

Na mesma direção, Gasché (2008) nota que mesmo os profissionais que trabalham junto à questão indígena, por exemplo, não se dão conta das particularidades inerentes a outras epistemologias. Para o autor, "há que se reconhecer que os educadores interculturais ignoram essas propriedades sociopolíticas e culturais dos povos com os quais trabalham" (Gasché, 2008, p. 384, tradução minha). Para ele tal postura é muito grave, pois representa obstáculo à possibilidade de exercício de uma democracia ativa por parte dos indígenas (Gasché, 2008).

Consequentemente, ignorar modos próprios indígenas de expressão e organização do mundo reproduz processos históricos de exclusão. Nessa direção, para Echeita Sarrionandía e Sandoval Mena (2002, p. 32, tradução minha), “o fenômeno da exclusão social é mais amplo e não implica somente pobreza econômica, mas também todo tipo de problemas de acesso à habitação, à saúde, à educação e ao emprego".

Ercivaldo não foi igualmente aprovado na prova de inglês. Note-se que ele foi alfabetizado na língua materna e tem na língua xerente seu principal idioma de comunicação, especialmente entre seu povo. Ele foi alfabetizado em português apenas aos 19 anos, situação bastante comum para boa parte da população indígena brasileira. O português já é, portanto, seu segundo idioma, sendo obviamente importante em muitos contextos de comunicação fora da terra indígena akwẽ, como na cidade de Tocantínia, próxima de sua comunidade e na universidade.

A obrigatoriedade de uma língua de origem indo-europeia indica uma política linguística universitária que, dentre outras coisas, exclui contingentes populacionais específicos, apontando para uma política que desvaloriza a diferença, impondo obstáculos a determinados contingentes populacionais, mas não a outros.

A reprovação de Damsõkekwa fez com que o colegiado do PPGAS, no ano de 2014 , tratasse da questão. Havia um certo consenso sobre o fato de que um 
excelente candidato, do ponto de vista de sua capacidade para produzir antropologia assim como da possibilidade do programa em se abrir à populações anteriormente excluídas da universidade - como outros programas de antropologia social estavam começando a fazer pelo país -, não havia sido aprovado por conta de mecanismos ambíguos no processo de seleção, que acabava por seguir excluindo determinadas populações.

Em 2014, ainda, a partir das discussões mencionadas, o PPGAS buscou elaborar um edital com cotas, a fim de corrigir as imperfeições observadas no ano anterior. A UFG, através de sua procuradoria, não permitiu, entretanto, que o edital fosse lançado. $\mathrm{O}$ argumento era o de que o edital contemplando ações afirmativas não poderia ser lançado apenas em um programa da instituição, o que deveria gerar questionamentos para todos os outros programas de pós-graduação, ameaçando-os.

A solução era buscar tornar as ações afirmativas regulamentadas e institucionalizadas na UFG, ou seja, válidas para todos os programas de pós-graduação. A tarefa não parecia fácil, afinal, a princípio, imaginava-se que tal política fosse entendida e aceita de maneira distinta, de acordo com as áreas do conhecimento. Assim, se ela tem grande aceitação em um campo como o da antropologia social, poderia não ter em outros. Com o intenso e efetivo apoio da Pró-Reitoria de Pós-Graduação (PRPG), de professores e professoras da Faculdade de Ciências Sociais (FCS) e também de outras faculdades, buscou-se então, criar uma resolução que contemplasse todos os programas. Além disso, precisava-se criar um consenso de modo que a resolução fosse aprovada.

Por meio de um diálogo intenso entre os programas, mediado pela PRPG, ficou acordado que cada um teria autonomia para elaborar seu processo de seleção, o que acabava por garantir e (re)afirmar o discurso do mérito e da excelência acadêmica - acessado por alguns que se colocavam contra a política. Conforme $o$ artigo $3^{\circ}$ da resolução, por exemplo,

o processo seletivo dos Programas de Pós-Graduação será regido por edital específico, segundo os termos da Resolução Geral dos Cursos de Pós-Graduação da UFG, sendo garantida à coordenadoria, por meio do edital, a liberdade de definir critérios específicos para o ingresso dos discentes, considerando as especificidades das áreas do conhecimento e as diretrizes do órgão federal de avaliação e acompanhamento. (Universidade Federal de Goiás, 2015, p. 3). 
Ao mesmo tempo, garantia-se que, pelo menos, $20 \%$ das vagas de todos os processos seletivos da pós-graduação na UFG fossem destinados às cotas para populações de pretos, pardos e indígenas. A minuta da resolução foi debatida na Coordenação de Pesquisa e Pós-Graduação (CPPG) em novembro de 2014. O Conselho Universitário (Consuni) rapidamente aprovou a resolução para a referida política de cotas na pós-graduação no dia 24 de abril de 2015.

Os debates, a elaboração da resolução e a aprovação tiveram, ao longo do processo, base em alguns elementos interessantes para se entender o que se passa na UFG, mas também nas outras universidades brasileiras.

A noção de autonomia universitária foi acessada a fim de evidenciar a possibilidade de a UFG aprovar uma resolução até certo ponto inédita no país. As metas da erradicação da pobreza e da desigualdade e o princípio de democratização da educação foram também centrais, reafirmando a assunção de que a educação superior tem um grande potencial de mexer em estruturas sociais enraizadas. Além disso, o fato histórico de que no Brasil apenas a elite econômica acessa, ao menos até há pouco tempo, de maneira hegemônica, as universidades públicas, as quais de maneira geral possuem maior qualidade do que as particulares, foi um dos argumentos centrais.

A universidade desse ponto de vista atuava - atua muitas vezes - como um espaço de reprodução das relações de poder. Isso a despeito de muitas experiências de formação de um pensamento crítico, contribuindo para o entendimento da América Latina e do mundo.

Por fim, a resolução ressaltava uma interpretação da legislação brasileira, identificando uma lacuna nela. Se há cotas na graduação e em concursos públicos, deve haver cotas na pós-graduação.

A turma de 2017 do PPGAS possui dois mestrandos indígenas - um Apinajé e uma Krahô - e uma quilombola. O processo de seleção foi modificado de modo que o texto dissertativo da prova teórica foi substituído por um interpretativo. No caso dos candidatos indígenas, considerou-se que o português já é uma segunda língua, dispensando a obrigatoriedade de uma prova de seleção em inglês. E o projeto solicitado passou a valorizar também aspectos da trajetória do candidato.

Entende-se, no PPGAS, que há agora um processo de seleção mais adequado. As transformações em referência buscam estabelecer relações mais próximas entre o ensino superior e a realidade brasileira, afastando-se de concepções 
universitárias, baseadas sobretudo em categorias eurocentradas, as quais atuaram para que "a universidade tenha sido crucial no eventual deslocamento de formas de conhecimento existentes classificadas como tradicionais e entendidas como contrárias à modernidade" (Tlostanova; Mignolo, 2012, p. 234, tradução minha).

A enorme maioria dos outros programas de pós-graduação da universidade, entretanto, não possui pós-graduandos indígenas e/ou quilombolas, apontando para elementos contraditórios do processo brevemente descrito. Afinal, se os critérios e mecanismos de seleção, dentre outras coisas, não são modificados estruturalmente, pode-se questionar até que ponto a resolução é efetiva.

Nessa direção, segundo Santos (1989, p. 11), muitas vezes

a universidade não parece preparada para defrontar os desafios, tanto mais que estes apontam para transformações profundas e não para simples reformas parcelares. Aliás tal impreparação, mais do que conjuntural, parece ser estrutural, na medida em que a perenidade da instituição universitária, sobretudo no mundo ocidental, está associada à rigidez funcional e organizacional, à relativa impermeabilidade, às pressões externas, enfim, à aversão à mudança.

A universidade, de maneira geral, apresenta grandes obstáculos a mudanças estruturais. Possui, portanto, modelo e dinâmica conservadores. Para Kerr (1982, p. 152, tradução minha), no mesmo sentido, "das 85 instituições atuais que já existiam em 1520, com funções similares às que desempenham hoje, 70 são universidades".

Sendo assim, a questão-chave a ser tratada diz respeito à necessidade de transformação em estruturas de funcionamento da universidade para que as políticas de inclusão e permanência elaboradas para a democratização universitária saiam do plano retórico e se tornem concretas. Ao mesmo tempo, deve-se refletir de que forma as políticas de inclusão que vêm sendo implementadas se relacionam com a noção de diferença.

Nessa perspectiva, este texto busca tratar de duas experiências particulares e interessantes de política de acesso e permanência na UFG - o Programa UFGInclui e o Núcleo Takinahakỹ de Formação Superior Indígena. O desenvolvimento do estudo tem como base a análise de alguns documentos institucionais, algumas entrevistas semiestruturadas, a observação participante de alguns eventos e a descrição do funcionamento das duas políticas. 
Ambas as experiências apontam para transformações importantes no ensino superior, problematizando aspectos fundamentais da inclusão, permanência e democratização da universidade brasileira. Ambas apontam também para impactos, transformações, ambiguidades e limites específicos ao processo. A comparação entre as duas busca ressaltar a necessidade de transformações estruturais na dinâmica universitária, para uma real inclusão da diferença.

Note-se que a UFG já possuía algumas outras experiências que tratam da questão e, portanto, de maneira ainda fragmentada, gerava reflexões interessantes sobre as possibilidades, princípios, modos, procedimentos e impactos das políticas de inclusão. Alguns cursos foram sendo criados na década de 2000, como a graduação em Direito para Beneficiários da Reforma Agrária em 2006, na cidade de Goiás, e a graduação em Licenciatura em Educação do Campo em 2007. ${ }^{1}$

\section{O Programa UFGInclui}

O Programa UFGInclui, implantado efetivamente no concurso vestibular de 2009/1, está vinculado à Pró-Reitoria de Graduação (Prograd). Foi criado pela resolução Consuni $n^{\circ} 29 / 2008$ e seu funcionamento foi alterado ou complementado com as resoluções 20/2010, 18/2011 e 31/2012 (Universidade Federal de Goiás, 2012), indicando período importante de efetivação de políticas de inclusão na UFG e, mesmo, no país. Segundo a resolução,

o desafio da inclusão social é um dos temas centrais da reforma universitária e uma questão importante que a envolve é a necessidade de uma clara política de apoio ao estudante com vistas não somente ao seu acesso ao ensino superior, mas à sua permanência plena nos cursos de graduação das universidades públicas brasileiras até a conclusão dos mesmos. (Universidade Federal de Goiás, 2008, p. 5).

1 Além de algumas outras ações, como a de permanência dos estudantes de baixa renda na UFG; o Programa de Bolsas Alimentação; o Programa de Bolsas de Monitoria; o Programa Institucional de Iniciação Científica; o Programa de Bolsas de Licenciatura; o Programa de Bolsas de Extensão e Cultura; o Programa de Bolsa Permanência; o Programa de Bolsas de Estágio; Creche; a Moradia Estudantil; o Serviço Odontológico; o Restaurante Universitário; o Programa de Concessão de Passagens para Alunos da Graduação. 
O argumento central para a aprovação do programa se refere às "profundas desigualdades sociais quanto ao acesso e usufruto dos bens materiais e culturais que são produzidos socialmente" (Universidade Federal de Goiás, 2008, p. 5). Segundo Resende, Queiroz e Faria (2012, p. 122),

o Programa considerava ainda que a "exclusão social" ou a "desigualdade" seriam tanto mais graves em Goiás porque apenas 14,71\% dos 775.000 jovens com idades entre 18 e 24 anos teriam acesso ao ensino superior. E mais: que, na Região Centro-Oeste, $72,6 \%$ dos jovens realizavam o ensino médio em escola pública e constituíam um contingente predominantemente situado nas classes C, D e E; que as informações fornecidas pelo Centro de Seleção acerca dos inscritos e classificados nos processos seletivos no período de 2004 a 2008 apontavam para "uma predominância dos estudantes negros (pretos e pardos) como oriundos das classes de menores rendimentos"; que os negros (pretos e pardos) têm mais dificuldade para se classificarem nos cursos da UFG.

Para isso o programa abrange uma série de ações para a preparação, acesso e permanência de estudantes indígenas, negros e da escola pública na universidade. Tais ações contemplam desde a criação de curso preparatório, a isenção de taxas e a reformulação de provas do processo seletivo, a ampliação dos serviços de assistência estudantil, a divulgação das ações de inclusão social na instituição e nas comunidades, com oficinas que esclarecem como ingressar na UFG, por exemplo, e o acompanhamento da trajetória acadêmica dos ingressantes.

No início, o programa estabelecia uma reserva de $10 \%$ das vagas de cada curso para estudantes de escola pública e estudantes negros de escola pública. Além disso, havia (há ainda) a criação de uma vaga adicional em cada curso para indígenas e quilombolas, e quinze vagas reservadas no curso de Libras para estudantes surdos. Desde o concurso vestibular de 2013, passa-se a abranger especificamente apenas quilombolas e indígenas de escolas públicas, além de estudantes surdos no curso de Libras. Outros candidatos que optam pelas cotas são incluídos na Lei de Reserva de Vagas.

Se o número de ingressantes não era alto no início, em 2016 recebeu o maior grupo de estudantes, 84 indígenas e quilombolas. Um elemento importante para o crescimento é a divulgação dos estudantes veteranos, outro elemento é o aperfeiçoamento do programa. Com isso, a UFG atualmente conta com cerca 
de 60 estudantes indígenas de diversas populações e cerca de 100 quilombolas de distintos povos. Todos têm direito à estrutura proporcionada pelo programa, assim como, desde 2010, recebem a Bolsa Permanência, política vinculada ao Fundo Nacional de Desenvolvimento da Educação (FNDE) Ministério da Educação (MEC). Além disso, o programa atualmente busca criar mecanismos para garantir um "acolhimento imediato", garantindo moradia, alimentação e bolsa até quando o MEC disponibilizar a primeira bolsa.

O programa realiza reuniões anuais de avaliação dos resultados a fim de aperfeiçoar seus mecanismos e procedimentos. O Relatório final do Seminário de Avaliação UFGInclui 2015, referente ao ano em questão, por exemplo, teve como base

o seminário de avaliação UFGInclui 2015, realizado em 10 de dezembro de 2015, pela Pró-Reitoria de Graduação, com apoio do Coletivo União os Estudantes Indígenas e Quilombolas da UFG, [e] objetivou a análise do Programa UFGInclui a partir dos seguintes aspectos: apresentação crítica das ações desenvolvidas pela UFG diretamente relacionadas ao acesso e permanência dos acadêmicos indígenas e quilombolas; avaliação qualitativa por parte dos estudantes integrantes do Programa UFGInclui em relação ao seu acesso e permanência na UFG; integração solidária entre estudantes indígenas, quilombolas, surdos, professores, pesquisadores e demais interessados na promoção e aprimoramento do Programa UFGInclui (Relatório..., 2015, p. 2).

O relatório apresenta aspectos importantes do acesso e permanência dos acadêmicos indígenas e quilombolas, identificando obstáculos, os quais têm a ver em grande parte dos casos às demandas socioeconômicas, como acesso à casa do estudante, renda para os primeiros meses em Goiânia, dentre outros. Mesmo com a estrutura garantida pelo programa, há vários entraves para a permanência dos ingressantes, indicando a complexidade da situação na universidade e das políticas de inclusão e diferença.

A moradia estudantil, por exemplo, representa um problema sério a ser tratado, seja pelo fato de não contemplar todos os ingressantes, seja pelos conflitos internos decorrentes das relações entre coletivos culturalmente distintos. Além disso, não se consideram ainda particularidades bem como características das populações em referência, como a necessidade de moradia para casais 
com filhos e, também, para quilombolas da Grande Goiânia. Isso, pois a política habitacional não se destina a tais categorias.

Nessa direção, no final de 2016, o programa conquistou duas moradias estudantis. Uma se localiza no Campus 1 - Colemar Natal e Silva e outra no Campus 2 - Samambaia, aumentando o número das vagas ofertadas e garantindo a manutenção de relações entre os participantes, o que, parece, vai melhorar a situação, possibilitando uma convivência próxima entre as populações indígenas e quilombolas, de modo a que possam viver na cidade, de certa forma menos distantes das demandas e relações de suas populações.

Há problemas igualmente em relação ao preconceito, discriminação e racismo identificáveis nas relações entre essas populações e outros membros da comunidade universitária. Em encontro realizado com parte do coletivo UFGInclui, na aula da disciplina Antropologia e Educação, oferecida no PPGAS no ano de 2015, alguns desses obstáculos foram relatados. Eles se referiam sobretudo a episódios de preconceito e discriminação que acontecem tanto entre discentes como com relação à docentes, nestes casos especificamente, a partir da reafirmação de relações de poder entre docente e discente. Há casos, inclusive, que apontam para o fato de que a partir das relações de preconceito e racismo, estudantes do programa passam a ter problemas de fluxo na trajetória acadêmica, ficando estagnados em algum período do curso. Nessa direção, uma das reivindicações dos participantes é a qualificação de docentes, técnico-administrativos e funcionários terceirizados da UFG de modo que se mitiguem os conflitos decorrentes da falta de conhecimento das pessoas em como se lidar com a diferença.

O problema de fluxo, bastante sério, pois tem como consequência, muitas vezes, a evasão, tem a ver também, conforme relatado, com a rigidez dos currículos, baseados em dinâmicas disciplinares, conteudistas e repletas de requisitos e amarras. Assim, por exemplo, a reprovação em uma disciplina particular pode acarretar igualmente na estagnação do acadêmico em algum momento do curso. Conforme Lima, Bianchi e Herbetta (2014, p. 2),

ao longo deste processo o percentual de alunos que evadem é bastante significativo, pondo em questão a condição inclusiva que nomina o próprio programa que articula tais iniciativas. Os registros acerca dos caminhos pelos quais se constrói essa evasão foram mapeados pela UFG e podem ser percebidos por meio do gráfico abaixo, presente no referido estudo confeccionado pela Prograd. 


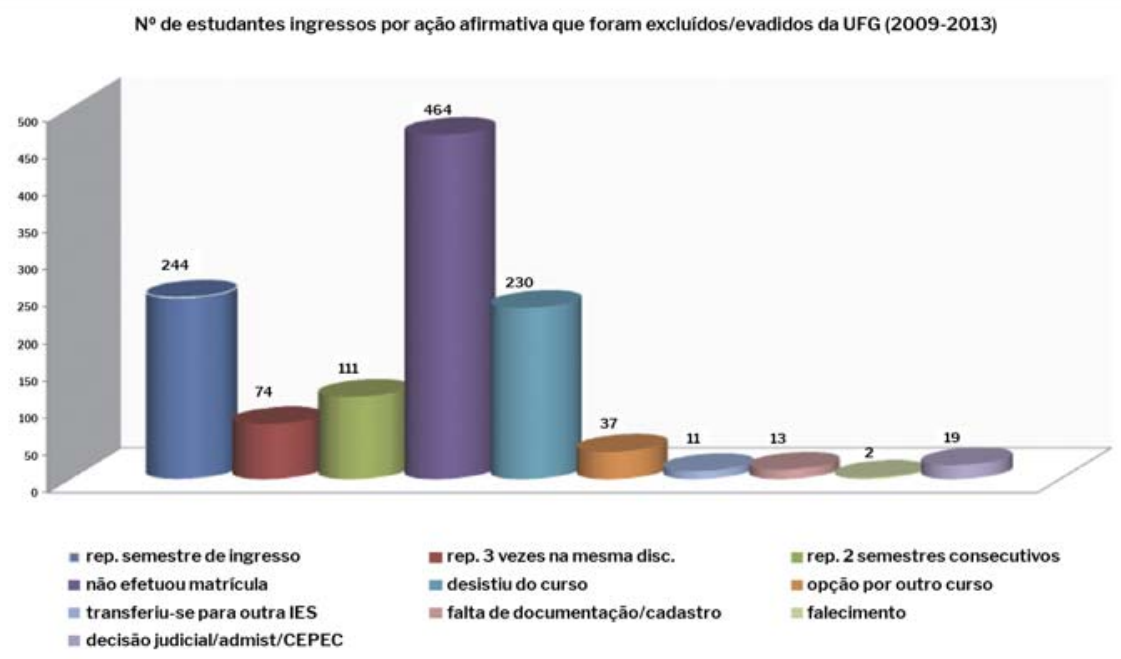

Gráfico 1. Evasão UFGInclui. Prograd.

Para os mesmos autores há uma grande variedade de elementos que atuam para a evasão dos alunos (Lima; Bianchi; Herbetta, 2014, p. 2). Tais elementos em alguns casos não possuem relação concreta com a universidade, como problemas de saúde e falecimento, mas na maioria dos casos têm relação direta com a estrutura e dinâmica universitária, o que implica inevitáveis questionamentos acerca da real condição inclusiva da UFG.

Ademais e na mesma direção, segundo Resende, Queiroz e Faria (2012), há mecanismos implícitos que fazem com que a exclusão se reproduza no interior do programa, de sorte que os cursos mais concorridos como medicina, engenharia e direito, por exemplo, sejam acessados por alunos com perfil que aponta para condições de renda superior, no espectro do perfil de estudante do programa. Segundo as autoras, pode-se observar um processo no qual em muitos casos "entre os 'excluídos', a exclusão se reproduz e a inclusão se efetiva de maneira desigual. Assim, os mecanismos de exclusão se repõem dentro das propostas das ações afirmativas que sugerem incluir todos" (Resende; Queiroz; Faria, 2012, p. 133).

O Programa UFGInclui vem passando por uma série de reformulações. Tais transformações buscam superar entraves para a permanência dos acadêmicos e acadêmicas na universidade, como a formação de um coletivo entre alunos negros e indígenas, denominado Coletivo União dos Estudantes Indígenas e 
Quilombolas da UFG - que funciona a partir de encontros presenciais, rodas de conversa e redes sociais, e fortalece sobremaneira o protagonismo dos estudantes no processo e na instituição-, além da destinação de um espaço físico, com estrutura adequada, no prédio do Centro de Convivência da UFG.

Tais conquistas são fundamentais para o desenvolvimento do programa e buscam superar os obstáculos identificados no processo de inclusão e permanência da instituição.

\section{O Núcleo Takinahakỹ de Formação Superior Indígena}

O NTFSI existe há dez anos e conta com cerca de 250 professores e professoras indígenas dos estados de Goiás, Mato Grosso, Tocantins e Maranhão. A maioria deles atua como docente na escola de suas comunidades. O núcleo está lotado na Faculdade de Letras (FL), por conta da formação de professores que o fundaram, assim como de aspectos burocráticos da UFG. Por conta disso, o núcleo não pode constituir um departamento independente, como parece ser o mais adequado. Note-se que o número de alunos corresponde a cerca de $30 \%$ dos alunos de toda a FL.

O Gráfico 2 apresenta o crescimento do número de alunos ao longo dos anos.

Total de alunos no Curso

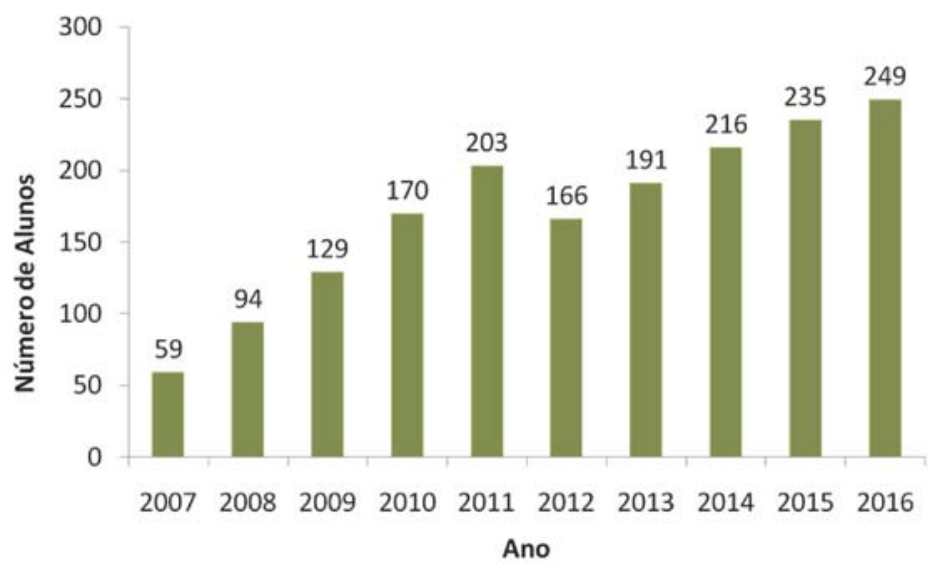

Gráfico 2. Total de alunos NTFSI (Bianchi, 2015). 
Note-se que é preponderante o ingresso de discentes do sexo masculino, apontando para interessante aspecto do campo da educação escolar indígena e, nesse caso, especificamente, do NTFSI. Vale apontar igualmente que os jovens são maioria no curso. Os dois marcadores - sexo e idade - ainda não contam com dados sistematizados, entretanto, visualmente são características marcantes e não variam substancialmente entre os povos que constituem o espaço.

O número de ingressantes (Gráfico 3) variou ao longo da década, se estabilizando entre 2013 e 2015 com a oferta de 60 vagas anuais. Tais vagas são oferecidas em concurso vestibular específico anual, o qual é realizado no final de cada ano em alguns polos distintos, como Imperatriz (MA), Palmas (TO) e São Félix (MT), de acordo com a demanda indígena. $\mathrm{O}$ vestibular é organizado pelo Centro de Seleção, mas é distinto do oferecido pela UFG para os outros cursos. Ele normalmente possui uma redação com tema ligado à questão indígena brasileira, uma entrevista e a análise de títulos, valorizando a experiência docente do candidato.

\section{Ingressantes no Curso}

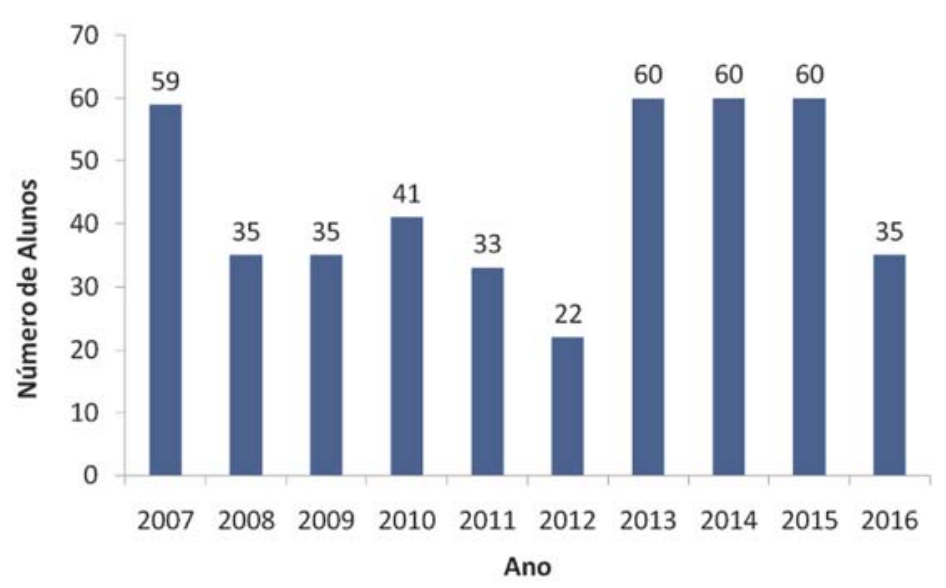

Gráfico 3. Ingressantes NTFSI (Bianchi, 2015).

O mesmo gráfico aponta também para uma pequena queda na oferta de vagas nos últimos dois anos. A queda no número de ingressantes enfraquece a política de inclusão da instituição e tem duas causas principais. Em primeiro lugar se refere ao não crescimento da estrutura do núcleo - número de professores efetivos, salas de 
aula, equipamentos e técnicos. Há 12 professores doutores com dedicação exclusiva, ligados diretamente ao núcleo, que possui um edifício constituído por salas de aula, de professores, secretaria e espaços de reunião. Nesse sentido, a estrutura se tornou pequena para o tamanho do curso. Em segundo lugar, tem a ver com a crise de recursos para a educação que assolou o país desde 2016, cortando receitas previstas.

O núcleo é constituído por curso de graduação e de pós-graduação no nível de especialização. O objetivo da especialização é o de produzir, junto com cada população indígena envolvida no projeto, o Projeto Político Pedagógico (PPP) de cada escola indígena. Essa proposta busca colaborar com uma transformação radical da escola indígena, a qual agora tem a possibilidade de existir com base em modos próprios de ensino e aprendizagem, assim como em conceitos atuais em relação ao campo em questão, como o da interculturalidade crítica (Walsh, 2013, p. 23-67), o da transdisciplinaridade e o da contextualização.

Note-se que a interculturalidade é tratada igualmente a partir da noção de relação de poder implícita nas relações interculturais, mesmo na universidade e, inclusive, no interior do NTFSI. Dessa forma, concorda-se com Gasché (2008, p. 373, tradução minha) quando ele afirma que "não podemos pensar a interculturalidade sem a relação dominação/submissão. Falar de interculturalidade como uma relação horizontal não é nada mais do que um eufemismo para disfarçar relações verticais". Da mesma forma, o NTFSI busca problematizar o senso muitas vezes existente em instituições de ensino sobre a existência de uma interculturalidade sem conflitos. Para o mesmo Gasché (2008, p. 376, tradução minha), esse senso equivocado seria "a utopia que sustenta o discurso educativo intercultural majoritário [mainstream] no mundo de hoje".

Atualmente, há cerca de 150 professores indígenas formados no nível da graduação - conforme a Tabela 1 - e 100 no nível da especialização.

Tabela 1. Egressos NTFSI (Bianchi, 2015).

\begin{tabular}{ccccc}
\hline \multicolumn{5}{c}{ Egressos da Educação Intercultural } \\
\hline TURMA & $\begin{array}{c}\text { CIÊNCIAS DA } \\
\text { CULTURA }\end{array}$ & $\begin{array}{c}\text { CIÊNCIAS DA } \\
\text { LINGUAGEM }\end{array}$ & $\begin{array}{c}\text { CIÊNCIAS DA } \\
\text { NATUREZA }\end{array}$ & TOTAL \\
\hline 2007 & 17 & 20 & 13 & 50 \\
\hline 2008 & 14 & 12 & 5 & 31 \\
\hline 2009 & 11 & 4 & 15 & 30 \\
\hline 2010 & 4 & 13 & 4 & 21 \\
\hline 2011 & 6 & 8 & 8 & 22 \\
\hline TOTAL & $\mathbf{5 2}$ & $\mathbf{5 7}$ & $\mathbf{4 5}$ & $\mathbf{1 5 4}$ \\
\hline
\end{tabular}


O espaço vem se constituindo como referência entre professores e professoras indígenas, assim como para intelectuais indígenas e não indígenas. Isso, a partir da consolidação de princípios e práticas inovadoras no campo da educação intercultural, o que faz igualmente com que, ao longo do tempo, o número de povos indígenas participantes do projeto, aumente - conforme mostrado a seguir (Quadro 1).

O NTFSI conta hoje com a participação de cerca de 21 distintas populações indígenas, entre elas, os Krahô, Apinajé, Javaé, Karajá, Kayapó, Guarani, Xambioá, Canela, Gavião, Guajajara, Juruna, Krikati, Mehinaku, Tapirapé, Xerente, Kamaiurá, Timbira, Waurá, Xavante, Xacriabá e Tapuia.

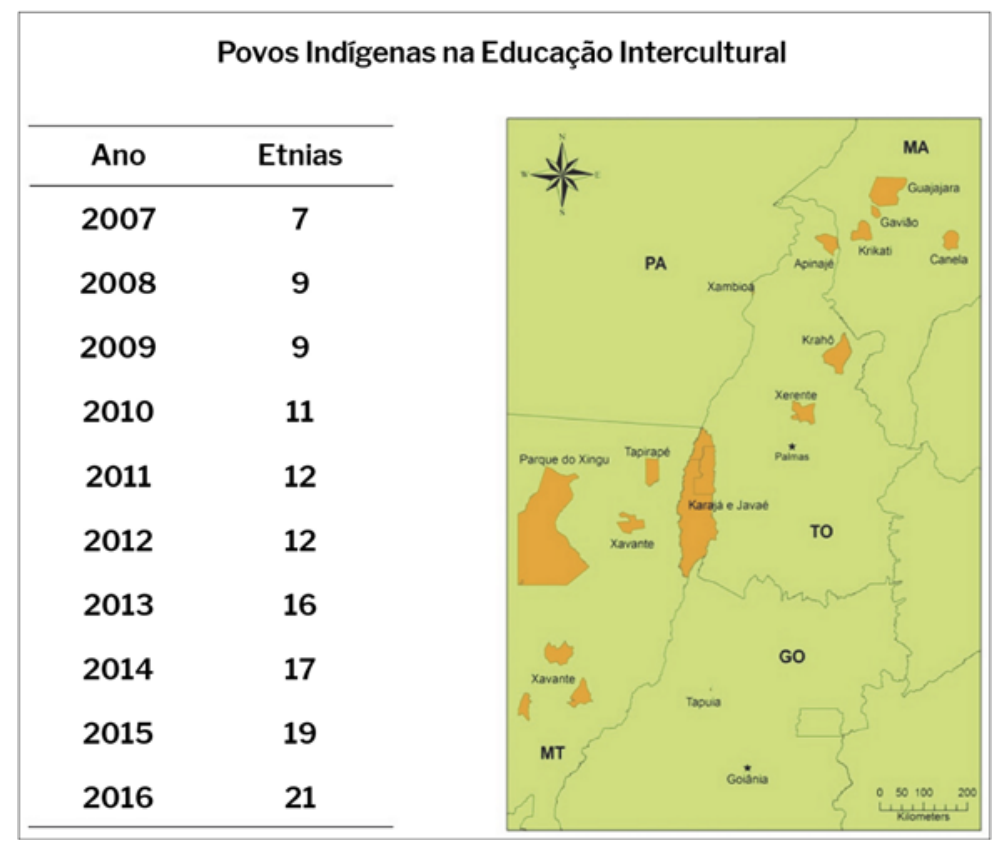

Quadro 1. Populações indígenas NTFSI (Bianchi, 2015).

A dinâmica de estudos é baseada na pedagogia da alternância. Duas etapas de estudo são realizadas em Goiânia, no Campus Samambaia. Elas se realizam nos períodos de janeiro-fevereiro e julho-agosto. Cada uma tem por volta de 35 dias. 
Nesses momentos, os acadêmicos indígenas se acomodam especialmente nos bairros Itatiaia e Alice Barbosa, próximos do campus, e transformam de maneira interessante as relações e paisagens da região, ocupando praças, bares, restaurantes e espaços convencionalmente não indígenas, o que é bastante marcante para a população não indígena desses lugares. Se o aspecto positivo é o estabelecimento de outras relações interétnicas, já que os acadêmicos indígenas são igualmente estudantes da UFG, status valorizado na região, o aspecto negativo é que se criam práticas de exploração efetivadas em aluguéis e outros serviços caros oferecidos aos indígenas.

Outras duas etapas são realizadas em terra indígena, de modo que professores efetivos e colaboradores do NTFSI se dividem entre as diversas populações e realizam atividades em cada uma das aldeias participantes. Nessas ocasiões é bastante importante o envolvimento da comunidade que participa de uma série de ações. Tal proposta tem como objetivo estabelecer relações próximas com a comunidade, de modo que as respectivas populações indígenas são sempre chamadas a participar das pesquisas, avaliações, seminários e, inclusive, das bancas de defesa. Essa proposta do NTFSI é bastante valorizada por todos os participantes e gera vínculos importantes entre professores indígenas e não indígenas e entre universidade e comunidade. É comum ouvir de anciãos e anciãs elogios referentes ao fato de que há um envolvimento concreto entre os diversos agentes mencionados.

O núcleo buscou se formar e tenta se desenvolver sempre em relação às epistemologias indígenas. Dessa forma, tem sua dinâmica voltada para o diálogo intercultural, o qual referencia o PPP do mesmo, a matriz curricular e as práticas pedagógicas elaboradas. Cada professor indígena cursa uma matriz básica de dois anos e uma matriz específica de mais três, quando opta por se aprofundar nas áreas da linguagem, natureza ou cultura.

Ao final do curso defende o trabalho extraescolar em sua comunidade, baseado na sistematização de um saber intra e intercultural, e apresenta um relatório de estágio, acerca de sua prática na escola indígena. Nesse sentido, a instituição universitária passa a aceitar uma defesa acadêmica realizada em outros espaços, os quais eram anteriormente invisibilizados nos procedimentos acadêmicos.

As defesas nas comunidades são organizadas coletivamente a partir das particularidades de cada população. Elas podem durar muitas horas e contar 
com cantoria, choro ritual, pintura corporal e outros elementos comuns aos ritos de cada povo. Ademais se deve notar que a banca é composta por professores não indígenas e por anciãos e anciãs indígenas e o procedimento pode ser todo realizado na língua materna, alterando bastante os ritos acadêmicos.

Além da interculturalidade, as noções de contextualização e de transdisciplinaridade são centrais para a operacionalização do curso. A interculturalidade é baseada em primeiro lugar na assunção de que a relação interétnica entre indígenas e não indígenas é conflituosa, como já mencionado. Em segundo, no esforço de se estabelecer um diálogo simétrico entre índios e não índios, do qual deve emergir aspectos centrais da epistemologia indígena. A contextualização tem como base a noção de que a situação em tela deve ter relação direta com a questão indígena contemporânea e a educação escolar indígena deve estar plenamente conectada às demandas das respectivas comunidades.

A transdisciplinaridade busca ser praticada a partir da ideia de que o currículo é formado por temas contextuais - e não disciplinas -, quais sejam, temas que pertencem ao universo cultural indígena, que não recorta o saber, mas o vive de forma associada e conectada. Essa dinâmica forma um currículo pautado nos temas da sustentabilidade e diversidade, oposto, portanto, às ideias de fragmentação dos saberes e universalização do conhecimento, implícitas na noção de disciplina.

Conforme Pimentel da Silva e Borges (2013, p. 63-92), os temas contextuais rompem com a tendência disciplinar de lidar com os conhecimentos. Desse modo, segundo a autora, os saberes indígenas entram na escola não pelos cânones hegemônicos da cientificidade tradicional, mas pela liberdade de se produzir outras contextualidades epistêmicas. Segundo o PPP do curso,

pretende-se com essa proposta curricular propiciar ao professor indígena uma formação que lhe dê condições para promover qualquer tipo de ensino, seja ele monolíngue, bilíngue, ou de qualquer outro tipo, independente da área que ele escolha para se especializar. Isso possibilitará ao professor não ser apenas um especialista, mas um profissional capaz de assessorar sua comunidade, como também lidar com os conhecimentos específicos de forma plural. O importante é que o professor tenha condições de colocar, efetivamente, a escola a serviço de 
sua comunidade, contribuindo com o desenvolvimento dos projetos de melhoria de vida. (Universidade Federal de Goiás, 2006, p. 32).

As atividades já mencionadas, assim como outros assuntos, tais como a logística de chegada de indígenas para a etapa em Goiânia e vice-versa, assim como questões pessoais, são tratadas no âmbito do que se chama comitê. Este é composto pelo grupo de professores e professoras indígenas pertencentes a um povo e por um ou dois professores não indígenas. O comitê reúne-se regularmente nas etapas a fim de tratar dos temas supracitados. E mantém contato ao longo do ano, entre as etapas, organizando eventos e outras atividades.

O comitê é constituído igualmente a partir da participação dos sábios da comunidade. São eles que legitimam ações e políticas estabelecidas nos grupos, assim como determinam demandas e atividades importantes para o desenvolvimento das atividades do NTFSI. Acabam também por criar uma rede entre gerações de uma mesma população e mesmo entre os distintos povos, já que por vezes professores de um comitê participam nas atividades de outros.

No âmbito do comitê observa-se claramente a interaprendizagem, cada população e sujeito contribuindo com o conhecimento do outro e se apropriando de novos saberes. Nessa direção, para Gasché (2008, p 392, tradução minha), "interaprendizagem é a palavra-chave que evoca o processo fundador de todo projeto de educação intercultural. Esse processo fundador expressa também uma relação de reciprocidade entre indígenas e não indígenas com benefício mútuo para expansão da capacidade de ação politica transcendente".

A dinâmica do comitê tem como objetivo produzir pesquisa/conhecimento de maneira coletiva acerca de temas relevantes para as comunidades, rompendo com pressupostos individualistas na produção e transmissão do conhecimento. O número de comitês vem crescendo ao longo dos anos, conforme se mostra a seguir (Gráfico 4). Isso de acordo com a entrada de novas populações indígenas, o que, se por um lado é muito positivo, permitindo o acesso de outras populações à universidade, as quais enriquecem sobremaneira as aulas e produções do núcleo, por outro lado representam os limites estruturais da instituição, os quais fazem, por exemplo, com que a oferta de vagas no vestibular venha diminuindo. 


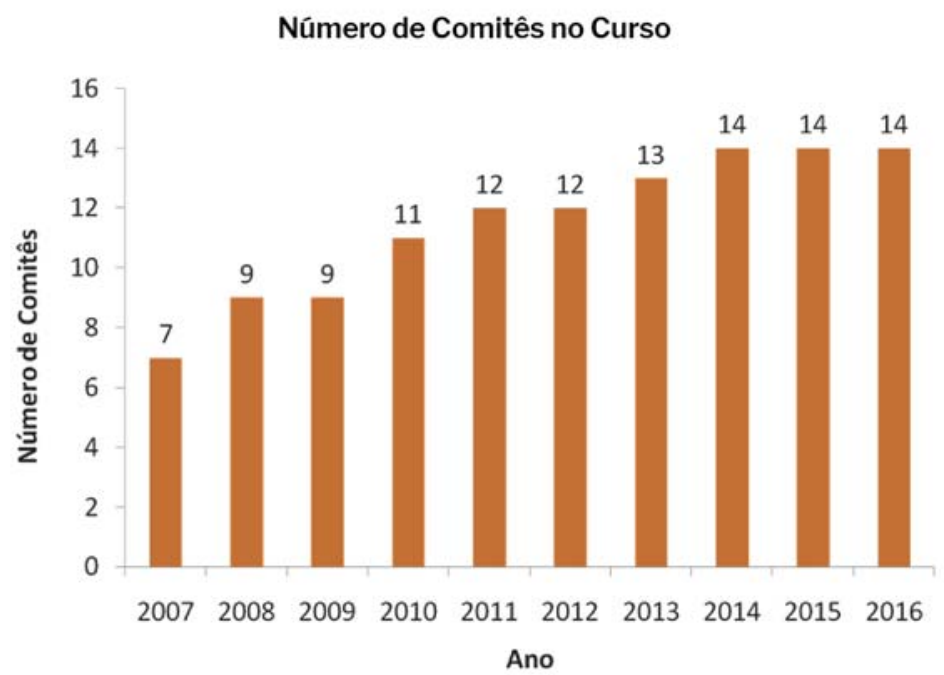

Gráfico 4. Comitês NTFSI (Bianchi, 2015).

Nesse cenário, no que se refere à evasão, o curso de Licenciatura Intercultural apresenta resultados inversos aos do UFGInclui e aos de muitos outros cursos da universidade, nos quais esse tema é um grande problema. $O$ índice de evasão do NTFSI é baixíssimo. Isso acontece pelo fato de que ali se promovem efetivamente transformações estruturais na dinâmica universitária, problematizando e rompendo com pressupostos e mecanismos convencionais da academia, como a dinâmica disciplinar dos currículos, a rigidez dos calendários, as políticas monolíngues que supervalorizam o português e, muitas vezes, o inglês e o francês, em detrimento de idiomas indígenas. E fortalecem-se também relações fundamentais para um efetivo processo de ensino e aprendizagem, como entre docentes e discentes, entre universidade e comunidade, assim como entre docentes indígenas e suas populações.

Além disso, a partir do NTFSI cria-se uma série de políticas editorias, as quais já são responsáveis pela produção de material didático e paradidático de autoria indígena, assim como livros e artigos acadêmicos de autoria indígena e não indígena, os quais refletem sobre a realidade da educação escolar, da educação intercultural, assim como sobre a questão indígena brasileira. O núcleo é, inclusive, um dos responsáveis pelo lançamento da revista Articulando e 
Construindo Saberes, que prima por uma política editorial inovadora, que contempla o conhecimento produzido em um diálogo intercultural e aceita os saberes produzidos nos diversos idiomas indígenas. Note-se então que há uma produção de literatura acadêmica em língua materna, rompendo com cânones da produção acadêmica tradicional.

A própria presença física do NTFSI, cujo prédio se diferencia dos outros da instituição por possuir especialmente uma oca central, espaço circular usado para reuniões, lançamentos de livros e periódicos, aulas e confraternizações, chama a atenção de outras pessoas da comunidade universitária. Muitas delas não possuíam nenhum conhecimento da questão indígena do país. Não são raros os casos de pessoas entrarem no núcleo e começarem um processo de conhecimento do tema em tela, alterando suas concepções sobre a situação indígena no país. Muitos estudantes de outros departamentos se aproximam igualmente produzindo seus TCCs, dissertações e teses, como a dissertação "Temos que ajuntar o conhecimento": professores indígenas e interculturalidade (Pereira, 2015), por exemplo, a qual busca analisar a formação dos acadêmicos indígenas a partir do conceito de interculturalidade.

\section{Considerações finais: políticas de transformação e diferença a partir das possibilidades e limites das ações de inclusão e permanência da UFG}

O texto buscou apresentar algumas políticas da UFG que se referem à inclusão e permanência de coletivos culturalmente diferenciados, como a instauração das cotas na pós-graduação, a criação de alguns programas, como o UFGInclui, e a criação de cursos diferenciados como o de Licenciatura em Educação do Campo e, especialmente, o Núcleo Takinahakỹ de Formação Superior Indígena. A partir do contexto particular da referida instituição, pode-se pensar, de maneira mais geral, na implementação de tais políticas no sistema de educação superior brasileiro e na noção de democratização da universidade. Deve-se notar igualmente a relação intrínseca entre políticas públicas e práticas acadêmicas.

Como se observa, o período que se inicia em meados dos anos 2000 é bastante importante do ponto de vista da implementação concreta de tais políticas 
e práticas, as quais apresentam melhora substancial no acesso e na permanência (um pouco menos) de coletivos culturalmente diferenciados e, simultaneamente, expõem contradições e tensões implícitas à estrutura universitária, as quais promovem obstáculos reais para a efetivação das ações. Para Santos (1989, p. 32), por exemplo, "nos últimos vinte anos a universidade tem-se vindo a confrontar com a progressiva erosão das dicotomias que sustentam a sua estabilidade e a sua especificidade institucionais: alta cultura/cultura popular; educação/trabalho; teoria/prática".

Note-se que essa situação se diferencia da realidade do sistema universitário em outras partes do mundo, já que "o plano Bolonha na Europa e o Encontro de Davos, no que se referem ao futuro da universidade, estão transformando a noção de aprendizagem em um instrumento para a eficiência e o desenvolvimento econômico, posicionando o 'conhecer para gerir' como central na universidade corporativa” (Tlostanova; Mignolo, 2012, p. 356, tradução minha).

Pode-se perceber igualmente que a universidade não é algo homogêneo, sendo constituída por diversas tendências e pessoas, as quais buscam, muitas vezes, solucionar seus dilemas e problemas. Assim, é a partir das situações particulares que se apresentam e da agência de pessoas e coletivos que obstáculos são solucionados e a instituição vai se transformando, como a instauração de cotas na pós-graduação, por exemplo.

Da comparação entre o Programa UFGInclui e o NTFSI pode-se aventar uma série de implicações, transformações e limites na estrutura universitária em tela. Pode-se afirmar, especialmente, a necessidade de transformações estruturais na universidade.

Ambas as experiências têm início em meados da década de 2000, indicando período importante para a efetivação de políticas que visam a democratização da universidade, como mencionado. Conforme observado, há várias outras experiências no período na UFG que se referem a práticas inclusivas, assim como acontece em outras universidades públicas brasileiras.

Todas elas buscam colaborar para que coletivos culturalmente diferenciados, como quilombolas e indígenas, assim como populações racializadas e marginalizadas, antes excluídas do espaço universitário, possam aceder e permanecer no ensino superior, constituindo suas trajetórias acadêmicas. O objetivo delas é o de transformar estruturas arcaicas de poder, nas quais as populações com caráter eurocentrado assumem as posições de maior poder 
na sociedade. Ao mesmo tempo, têm como eixo proporcionar a essas outras populações acesso a um capital cultural e social valorizado, o conhecimento acadêmico. Para Castro-Gómez (2005, p. 119, tradução minha), por exemplo, “a instituição universitária funcionava na Colônia como um rígido mecanismo de legitimação da brancura como capital cultural herdado".

Busca-se sobretudo transformar o espaço universitário. Para Santos (1989, p. 45),

a universidade foi criticada, quer por raramente ter cuidado de mobilizar os conhecimentos acumulados a favor de soluções dos problemas sociais, quer por não ter sabido ou querido pôr a sua autonomia institucional e a sua tradição de espírito crítico e de discussão livre e desinteressada ao serviço dos grupos sociais dominados e seus interesses.

No contexto aqui apresentado, o Programa UFGInclui busca se transformar a partir das demandas apresentadas pelos ingressantes no programa. Tais demandas têm relação sobretudo (mas não só) a aspectos socioeconômicos, fundamentais para a permanência das diversas populações na cidade de estudo e para garantir condições de sobrevivência digna a elas. Nesse sentido, percebe-se claramente que o programa vem ao longo do tempo tendo importantes conquistas, como a casa estudantil, políticas de acolhimento imediato, espaços físicos na universidade entre outros.

Simultaneamente, percebe-se que se apresentam regularmente alguns obstáculos mais difíceis de superação, como: 1) a falta de conhecimento de grande parte da população não indígena e não quilombola dos contextos particulares em questão, o que gera, em muitos momentos, casos de discriminação e racismo; 2) a, às vezes, difícil relação entre discentes e docentes, o que em alguns casos pode gerar um entrave na trajetória acadêmica do discente; 3) a própria rigidez da estrutura universitária, que tem dificuldades e mesmo impossibilidade de entendimento de outras epistemologias, o que faz com que o aluno culturalmente diferenciado deva obrigatoriamente se adaptar a práticas burocráticas, avaliativas, pedagógicas e culturais distintas da sua.

Nessa direção vale destacar, por exemplo, que o regime disciplinar e conteudista característico da academia, assim como as noções e individualização, presente muitas vezes no sistema de avaliação e excelência, presente no 
discurso de produção do conhecimento acadêmico, se afasta dos regimes de conhecimento ameríndios (e quilombolas), prejudicando a trajetória acadêmica dos estudantes. Segundo Krenak (2015, p. 147), "a solidariedade indígena está fundada em princípios que não são os princípios do confronto; não são os princípios da perspectiva da revolução burguesa, da revolução moderna".

Pode-se dizer, portanto, que se o Programa UFGInclui é bastante importante no que se refere a inclusão e permanência, cumprindo papel relevante para o acesso de populações antes excluídas do espaço universitário, e simultaneamente apresenta limites quase intransponíveis, que se referem sobretudo a uma concepção antiga e estática de universidade e a uma perspectiva que ignora efetivamente a diferença. Nessa direção, para Tlostanova e Mignolo (2012 p. 245, tradução minha), "a lógica da epistemologia ocidental e imperial consiste na efetivação de um metadiscurso que se autovalida desqualificando a diferença".

Sendo assim, as transformações observadas no Programa UFGInclui são mais pontuais e a inclusão traz um caráter de integração. Tal situação ambígua se apresenta em outros espaços acadêmicos. Carvalho (2005-2006, p. 88-103) já havia notado o número incrivelmente baixo de docentes negros em instituições universitárias, mesmo após anos de discussão e política de cotas. Munduruku observou algo similar em relação a muitos cursos destinados às populações indígenas. Segundo ele,

basta lembrar, para isso, que o domínio da escrita do pariwat é justificado pela necessidade de ler a realidade brasileira que, a priori, não faz parte do imaginário indígena. De modo que, a meu ver, foi-se criando uma necessidade nos jovens nativos de apreender conceitos e teorias que não cabem no pensar holístico e circular de seus povos. Esta agressão ao sistema mental indígena, fruto de uma história da qual não somos culpados, mas sobre qual temos responsabilidade, acaba se perpetuando nas novas políticas inclusivistas levados [sic] a efeito por governos nas três esferas. Conclusão: nossos jovens se vêm [sic] obrigados a aceitar como inevitável à [sic] necessidade de ler e escrever códigos das [sic] quais prefeririam não aprender e não lhes é dado o direito de recusar sob a acusação de preguiça ou descaso para com a "boa vontade" dos governos e governantes. (Munduruku, [s.d.]).

Conforme a afirmação acima, o processo de acesso, permanência e formação superior indígena, assim como ações no âmbito da educação escolar, pode, a 
despeito de uma retórica interessante, cair no erro de impor os códigos e modelos de uma epistemologia eurocentrada, reproduzindo a mesma dinâmica de dominação presente nas políticas integracionistas, que imputavam às populações indígenas outros saberes em detrimento dos modos próprios de se conceber o mundo.

O NTFSI por sua vez constitui uma experiência distinta dentro da instituição. Como se pôde observar, busca promover transformações estruturais na universidade. Em primeiro lugar, não trabalha a partir da dinâmica disciplinar, convencional no meio acadêmico ocidental. O núcleo possui uma matriz curricular baseada na dinâmica do que se chama "tema contextual", a qual, dentre outras coisas, rompe com a hierarquização e fragmentação dos saberes, constituindo uma proposta de transdisciplinaridade. Assim, a matemática não é mais importante do que a música, por exemplo. $\mathrm{E}$ a formação acadêmica é baseada em temas que têm relação mais próxima com as demandas indígenas do país, assim como com a formação de professores indígenas para as escolas das comunidades.

Para Lewis Gordon (2011), o regime disciplinar aponta para um modo de produção e organização do conhecimento vinculado aos saberes ocidentais e à noção de modernidade, reforçando categorias como hierarquia e descontextualizando a realidade. Nesse sentido, para o autor a disciplina reduz os saberes ao ocidental e fortalece a noção de poder, baseada no que chama de fetichização do método, quando este é mais importante do que o resultado.

A dinâmica do NTFSI busca também romper com a excessiva individualização do processo de produção e transmissão do conhecimento. Como se viu, a noção de comitê é base para o funcionamento do curso. Ela indica uma tendência à prática coletiva que se dá desde a orientação dos trabalhos até o desenvolvimento das pesquisas e logística das etapas. Além disso, há claramente uma política linguística bastante inovadora. E uma política editorial que problematiza e rompe com a dinâmica da produção acadêmica ocidental.

A percepção de acadêmicos indígenas do NTFSI, assim como de intelectuais indígenas e não indígenas que conhecem a dinâmica do núcleo, é bastante positiva e chama a atenção. Da mesma maneira, o índice de evasão é mínimo. Nessa perspectiva, para Santos (1989, p. 65), "é necessário repensar inovadora e radicalmente a idéia de universidade para que esta se possa transformar numa universidade de idéias". 
Como mencionado, é fundamental a agência de pessoas e coletivos para a transformação da universidade e o aperfeiçoamento das políticas de inclusão e diferença. É a partir de ações e demandas específicas que se podem desencadear modificações importantes, as quais problematizam e rompem com elementos fundantes de uma universidade elitista e excludente.

Damsõkekwa, por exemplo, mencionado no início do texto, insistiu de maneira perseverante em seu desejo de cursar a pós-graduação e, em 2014, foi aprovado na seleção do Programa de Pós-Graduação Interdisciplinar em Direitos Humanos, ligado ao Núcleo Interdisciplinar de Estudos e Pesquisas em Direitos Humanos, lotado na PRPG.

Em dezembro de 2016, Ercivaldo defendeu sua dissertação, intitulada Processos de educação akwẽ e os direitos indígenas a uma educação diferenciada: práticas educativas tradicionais e suas relações com a prática escolar, pela qual foi aprovado com louvor. Tornou-se assim o primeiro Xerente a obter o título de mestre, assumindo status diferenciado em sua comunidade e região.

Conforme Damsõkekwa Xerente (2016, p. 3), o estudo teve

o objetivo de compreender as relações entre o seu modelo próprio de educação, baseado na oralidade, e os modelos e práticas educativas escolarizadas, baseadas na escrita. Para tanto, faço uma descrição do sistema e dos processos tradicionais de formação e socialização dos jovens Akwẽ e do Warã, instituição educativa, conduzida pelos velhos que são responsáveis por essa formação. Também observei as práticas cotidianas da aldeia Kakumhu/Riozinho e da escola Wakõmẽkwa, locais escolhidos para realização da pesquisa etnográfica.

A população xerente possui agora mais uma base de conhecimentos sistematizado para pensar seus processos de ensino e aprendizagem e o papel da escola na comunidade. Intelectuais indígenas e não indígenas possuem mais subsídios para pensar o campo de estudos em tela. E a universidade tem a potencialidade de se transformar a partir das novas ideias e práticas propostas. Há outros egressos do NTFSI em programas de pós-graduação pelo país, em linguística, antropologia, letras e estudos ambientais, distribuídos em distintas universidades, como a UFG, Universidade Federal do Tocantins (UFT) e Universidade Federal do Rio de Janeiro (UFRJ). Há egressos do UFGInclui entrando igualmente na pós-graduação. 
Se o cenário apresentado aponta ambiguidades e limites, os quais evidenciam a complexidade da situação, a atuação dos agentes e coletivos, e a criação e reelaboração de políticas e práticas para a inclusão e permanência, indicam que a universidade vem tentando ser um espaço mais democrático. Ao mesmo tempo, fica evidente que para que tais políticas não tenham um caráter integracionista, buscando apenas apagar a diferença, como historicamente foi (e ainda é na maioria dos casos) a relação entre o Estado e tais contingentes populacionais, é necessário a transformação de estruturas acadêmicas, para se efetivar concretamente a inclusão das diferenças.

Conclui-se, portanto, que a questão universitária é relacionada à noção de poder e a forma como este é exercido na sociedade. Nesse contexto, uma universidade mais democrática é uma possibilidade real no mundo contemporâneo apenas se houver vontade política dos agentes envolvidos - políticos, gestores, docentes e discentes. Isso, a despeito dos entraves estruturais e históricos, e do caráter ainda elitista da instituição.

Para Gasché (2008, p. 381, tradução minha), "controlar o uso egoísta do poder consiste, então, em contrariar a dominação e incorporar a justiça, o direito, o respeito, a igualdade e sobretudo o uso democrático do poder frente a todas as formas de abuso do poder egoísta". Para o autor o poder egoísta é próprio da sociedade colonial e ocidental, e configura "a dominação de quem é privilegiado sobre quem não é" (Gasché, 2008, p. 378, tradução minha).

Apenas uma universidade que inclui concreta e efetivamente a diferença, desde um ponto de vista político e epistemológico, qual seja o de transformar suas dinâmicas estruturais levando em consideração também os modos próprios de se pensar o mundo de outros contingentes populacionais, culturalmente diferenciados, pode contribuir para uma sociedade mais tolerante, equilibrada e para um uso mais consciente do poder.

\section{Referências}

BIANCHI, C. Apresentação do NTFSI. 2015. Seminário do Núcleo Takinahakỹ, Universidade Federal de Goiás, Goiânia, agosto de 2015.

CARVALHO, J. J. O confinamento racial do mundo acadêmico brasileiro. Revista USP, São Paulo, n. 68, p. 88-103, dez./fev. 2005-2006. 
CASTRO-GÓMEZ, S. La hybris del punto cero: ciencia, raza e ilustración en la Nueva Granada (1750-1816). Bogotá: Editorial Pontificia Universidad Javeriana, 2005.

ECHEITA SARRIONANDÍA, G.; SANDOVAL MENA, M. Educación inclusiva o educación sin exclusiones. Revista de Educación, Madrid, n. 327, p. 31-48, 2002.

GASCHÉ, J. La motivación política de la educación inetrcultural indígena y sus exigencias pedagógicas hasta dónde abarca la interculturalidad. In: BERTELY, M.; GASCHÉ, J.; PODESTÁ, R. Educando en la diversidad cultural: investigaciones y experiencias educativas interculturales y bilingües. Ecuador: Abya-Yala, 2008. p. 367-397.

GORDON, L. Shifting the geography of reason in an age of disciplinary decadence. Transmodernity: Journal of Peripherical Cultural Production of the Luso-Hispanico World, Merced, v. 1, n. 2, p. 95-103, 2011.

KERR, C. The uses of the university. Cambridge: Harvard University Press, 1982.

KRENAK, A. Encontros Ailton Krenak. Rio de Janeiro: Azougue, 2015. (Coleção Encontros, v. 50).

LIMA, G.; BIANCHI, C. A.; HERBETTA, A. Comparação preliminar entre o Programa UFGInclui e o NTFSI. Monografia apresentada ao Curso de Formação de Docentes da UFG. Requisito obrigatório ao Estágio Docência. Goiânia: Universidade Federal de Goiás, 2014.

MUNDURUKU, D. A escrita e a autoria fortalecendo a identidade. [s.d.]. Disponível em: $<$ http://pib.socioambiental.org/pt/c/iniciativas-indigenas/autoria-indigena/a-escrita-e-a-autoria-fortalecendo-a-identidade>. Acesso em: 30 dez. 2009.

PEREIRA, D. R. Temos que ajuntar o conhecimento: professores indígenas e interculturalidade. 2015. Dissertação (Mestrado em Antropologia Social)-Faculdade de Ciências Sociais, Universidade Federal de Goiás, 2015.

PIMENTEL DA SILVA, M. do S.; BORGES, M. V. (Org.). Educação intercultural: experiências e desafios políticos pedagógicos. Goiânia: Prolind: Secad-Mec: Funape, 2013.

RAMOS, A. Mentes indígenas e ecúmeno antropológico. Brasília: Universidade de Brasília, 2013. (Série Antropologia, 439).

RELATÓRIO final do seminário de avaliação UFGInclui 2015. Goiânia: Universidade Federal de Goiás, 2015. Disponível em: <https://prograd.ufg.br/up/90/o/ relato\%CC\%81rio_ufgInclui_2015.pdf>. Acesso em: 10 mar. 2017.

RESENDE, A. C. A.; QUEIROZ, E. M. O.; FARIA, G. G. G. A dialética inclusão/exclusão na experiência do Programa UFGInclui. Revista Brasileira de Estudos Pedagógicos, Brasília, v. 93, n. 233, p. 120-134, jan./abr. 2012. 
SANTOS, B. de S. Da Ideia de Universidade à Universidade de Ideias. Revista Crítica de Ciências Sociais, Coimbra, n. 27/28, p. 11-62, jun. 1989.

TLOSTANOVA, M. V.; MIGNOLO, W. D. Learning to unlearn: decolonial reflections from Eurasia and the Americas. Columbus: The Ohio State University Press, 2012. (Transoceanic Studies).

UNIVERSIDADE FEDERAL DE GOIÁS. Pró-Reitoria de Graduação. Núcleo Takinahakỹ de Formação Superior Indígena. Projeto político-pedagógico educação intercultural. Goiânia, 2006.

UNIVERSIDADE FEDERAL DE GOIÁS. Resolução Consuni nº 29/2008. Cria o Programa "UFGInclui" na Universidade Federal de Goiás e dá outras providências. Goiânia, 2008.

UNIVERSIDADE FEDERAL DE GOIÁS. Resolução Consuni n 31/2012. Altera a Resolução CONSUNI N 29/2008, modificada pelas Resoluções 20/2010 e 18/2011, que dispõem sobre o Programa UFGInclui na UFG. Goiânia, 2012.

UNIVERSIDADE FEDERAL DE GOIÁS. Resolução Consuni $n^{\circ}$ 07/2015. Dispõe sobre a política de ações afirmativas para pretos, pardos e indígenas na Pós-Graduação stricto sensu na UFG. Goiânia, 2015.

WALSH, C. Pedagogías decoloniales: prácticas insurgentes de resistir, (re)existir y (re) vivir. Quito: Abya-Yala, 2013. (Serie Pensamiento Decolonial).

XERENTE, E. D. C. Processos de educação akwẽ e os direitos indigenas a uma educação diferenciada: práticas educativas tradicionais e suas relações com a prática escolar. 2016. Dissertação (Mestrado em Direitos Humanos)-Núcleo Interdisciplinar de Estudos e Pesquisas em Direitos Humanos, Universidade Federal de Goiás, Goiânia, 2016. 